\title{
Stage II Chronic Lymphocytic Leukemia
}

National Cancer Institute

\section{Source}

National Cancer Institute. Stage I/ Chronic Lymphocytic Leukemia. NCI Thesaurus. Code C7875.

Risk: Intermediate; Findings: Lymphocytosis, adenopathy, and enlarged spleen and/or liver; Survival (months): 72. (from AJCC 8th Ed.) 